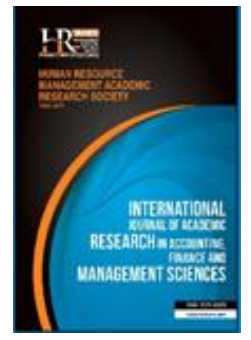

International Journal of Academic Research in Accounting, Finance and Management Sciences

Vol. 8, No.3, July 2018, pp. 53-62

E-ISSN: 2225-8329, P-ISSN: 2308-0337

(c) 2018 HRMARS

www.hrmars.com

To cite this article: lacob. Ș.V. (2018). The Spectral Analysis of Labor Force and Profit of Construction Materials Distribution Companies in Romania Analogue Spectrum of Light in Physics, International Journal of Academic Research in Accounting, Finance and Management Sciences 8 (3): 53-62.

\title{
The Spectral Analysis of Labor Force and Profit of Construction Materials Distribution Companies in Romania Analogue Spectrum of Light in Physics
}

Ștefan Virgil IACOB

The Bucharest University of Economic Studies, Romania, E-mail: stefaniacob79@yahoo.com

\begin{abstract}
In physics, spectral studies have been observed and quantified since 1822 when Fourier J. (1822) used them in his analysis of thermal conduction. Further, Balmer (1885), studying the hydrogen atom, noticed the existence of the four lengths waveform which characterize the spectrum of the hydrogen atom. Following the research, it determined the number of $364.6 \mathrm{~nm}$ that was identified in each hydrogen spectral line. Therefore, Balmer determined the equation to determine the wavelength of the emission or absorption lines. Three years later, physicist Johannes Rydberg generalized Balmer's equation, thus determining the constant Rydberg. Rutherford's model was later improved and in 1913 was introduced Bohr's model and converts justify empirical results in terms of fundamental physical constants. Subsequently, a significant number of physicists approached the spectral analyzes of electromagnetic radiation (in different fields: ultraviolet, $X$-rays, infrared) and analyzed their characteristics: frequency, amplitude, spectral density. In the economy, the first papers that dealt with spectral analysis emerged in 1960 and consisted of the analysis of seasonal adjustment procedures for time series at macroeconomic level. Starting from the cross-spectral methods were developed methods such as analysis of the movement in the series, the time-frequency methods, etc. The fluctuating nature of the activities of different sectors of activity involves different oscillations in terms of amplitude and frequency, but also oscillations characterized by a higher or lower propagation period, which determines the evolution of economic indicators. We can classify the propagation periods of activities according to the level of the characteristics that determine them in time units (time intervals). Thus, the oscillation frequency will be given by the number of periods of propagation activities. Depending on the oscillation period will determine their average, and the amplitude of oscillation is determined by peak line and the average determined. Starting from the ultraviolet spectrum in physics and the spectral analyzes made by physicists, analogy we find in the economy elements that refer to the fervent oscillations and form "color strips" and "spectrum". To make "spectral analysis" of such a fluctuating process in terms of frequency and amplitude need a sufficient number of numerical data on the evolution of an economic process.
\end{abstract}

Key words Oscillations, frequencies, spectrum, wave, amplitudes, power, density, functions, variables, coefficients, workforce, employees, profit and loss

Received: $20 \mathrm{Jul} 2018 \quad$ (C) The Authors 2018

Revised: 20 Aug 2018 Published by Human Resource Management Academic Research Society (www.hrmars.com

Accepted: 25 Aug 2018 This article is published under the Creative Commons Attribution (CC BY 4.0) license. Anyone may reproduce, distribute, translate and create derivative works of this article (for both commercial and noncommercial purposes), subject to full attribution to the original publication and authors. The full terms of this license may be seen at: $\underline{\text { http://creativecommons.org/licences/by/4.0/legalcode }}$

\section{Introduction}

In this paper I will apply the methods of "spectral analysis" of the indicators of a Romanian company that operates in the field of trade with materials for light, medium and heavy metal constructions. I will consider in the following evolution of the number of employees of the distribution of building materials for the period between 2010 and 2017 and financial - accounting result in terms of profit and loss between the years 2013 and 2017. 
The analyzed period precedes the economic crisis from 2008 to 2009 and was characterized by steady increases in the business figures of the companies in the field. In Romania, the existence of the four seasons has an influence on the activity of the construction companies, which in turn influence the distribution companies, especially if this is done outdoors. In the cold season, there are decreases in rollingoffs since concrete tunneling, welding on site in the construction site are under difficult conditions with additional work protection measures or are effectively blocked. All these measures involve high costs and lead construction companies in unprofitable areas, often preferring to block the yard. Spring begins the period of relaunching civil and industrial construction, which is also felt in the revenues of the companies selling the metallurgical materials. The upward trend is kept throughout the summer, where there are small fluctuations due to the very hot periods where we find a situation similar to the cold season, but not the same amplitude. In the last period of the year the maximum amount of receipts is recorded, followed by the decrease of the values collected with the coming of winter.

In this paper I will make the spectral analysis of a commercial company in the field of metal building materials and will determine to what extent the indicators: the number of employees and the profit of the analyzed company are affected by seasonality and cyclicality. The results of the analysis are to highlight the extent to which these economic phenomena infuse the company's development.

\section{Literature review}

Gheorghiu and Spanulescu (2007) studied aspects regarding the application of physics and mathematics in economic theories. Isaic-Maniu et al. (2004) analyzes indexes and calculates them as a ratio of two averages, indices of value, physical volume and prices. In terms of spectral analysis in the study of physical and economic phenomena, a number of contributions can be mentioned. For example: in his work, Roman physicist Danet (2010), made a thorough analysis of spectrometric methods, starting from electromagnetic radiation and electromagnetic spectrum. Crenga et al. (2001) addresses the problem of spectral modeling of signals. Thus, spectral analysis of analog, numerical and non-stationary signals was performed. Granger and Hatanaka (1964) addresses the problems encountered in analyzing economic data in the form of time series, using spectral analysis methods developed by communications engineering in time series analysis. English statistician Priestley M.B. (1971) has taken over from classical physics the concept of "power spectrum" that at that time was applicable only to stationary processes and generalized this theory to processes whose statistical properties vary over time. lacobucci (2003) conducted a spectral analysis of economic time series by addressing business cycle filtering issues and cross-spectral analysis introducing concepts such as "phase coherence and spectrum." In the sphere of concern of the Romanian economist Pecican (2009), spectral analyzes also took into account the possibility of estimating an oscillation. Business cycle models were also addressed by Wang (2010) applying to UK sectoral production using spectrum, based on UK GDP production data, following the extent to which the conditions of a white noise.

\section{Research methodology, data, results and discussions}

In physics, spectral studies have been observed and quantified since the 19th century by the French mathematician who proposed them are used in the analysis of periodic functions.

Sometime later, studying the Balmer hydrogen atom (1885), he noticed that there are four wavelengths that characterize the spectrum of hydrogen atoms. Thus, according to the research, there is a number found in each spectral line of hydrogen, namely $364.6 \mathrm{~nm}$. Starting from this point, Balmer determined the equation that bears his name, and by which the wavelength of the emission or absorption lines can be determined:

$$
\lambda=B\left(\frac{n^{2}}{n^{2}-m^{2}}\right)
$$

Where: $\lambda$ is the wave length;

$B$ is a constant with the value of $3.6450682 \times 10-7 \mathrm{~m}$ or $364.50682 \mathrm{~nm}$;

$m$ is equal to 2 ;

$n$ is an integer such that $n>m$. 
The development of a Fourier $\mathrm{F}$ function has the form:

$f(x)=\frac{a_{0}}{2}+\sum_{n=1}^{\infty}\left(a_{n} \cos n x+b_{n} \sin n x\right)$

Where: $a_{0}, a_{n}, b_{n}$ are the Euler Fourier coefficients of the function $\mathrm{f}(\mathrm{x})$;

$n$ is the angular frequency given by the relationship:

$n=f \frac{2 \pi}{T}$

Where: $f=$ frequency; $T=$ the duration of the interval.

The coefficients of the function $f(x)$ are calculated using the Euler-Fourier formulas, taking into account the fact that there are more oscillations with different frequencies in the economic processes, so the "periodic wave" of the process is modeled by these oscillations whose different frequencies presents similarities. Continuing reasoning, such a oscillating evolution determined by the numerical string can be written in the form of a finite sum of sinus and cosine functions:

$$
y_{t}=\frac{a_{0}}{2}+\sum_{f=1}^{p}\left(a_{f} \cos \frac{2 \pi}{T} f t+b_{f} \sin \frac{2 \pi}{T} f t\right)+u_{t}
$$

Where: $a_{0}, a_{f}, b_{f}$ represent the parameters;

T represents the number of time units;

$f$ is the frequency initially set and $t$ has values within the range $[1, T]$.

We follow the estimates of $\hat{a}_{f}, \hat{b}_{f}$ which result in the approximation of the function $f(t)$ by the finite sum of sinus and cosine functions, which will be denoted by $\mathrm{y}_{n(t)}$. Analog to the least squares method we follow the whole:

$$
\frac{1}{2 \pi} \int_{0}^{2 \pi}\left[f_{(t)}-y_{n(t)}\right]^{2} d t
$$

The minimum value of the integral is reached when $a_{f}, b_{f}$, is the Euler-Fourier coefficients of the function $f(t)$, so we can determine the estimated coefficients:

$$
\begin{aligned}
& \hat{a}_{f}=\frac{2}{T} \sum_{t=1}^{T} y_{t} \cos \frac{2 \pi}{T} f t \\
& \hat{b}_{f}=\frac{2}{T} \sum_{t=1}^{T} y_{t} \sin \frac{2 \pi}{T} f t \\
& \hat{a}_{0}=\frac{\sum y_{t}}{T}
\end{aligned}
$$

Fourier coefficients are required for the determination of specific "spectral analysis" indicators such as amplitude:

$$
A_{f}=\sqrt{\hat{a}_{f}^{2}+\widehat{b}_{f}^{2}}
$$

The "power of the spectrum" is correlated with the intensity of the dispersion of the analyzed harmonic components and is determined with the relation: 


$$
\begin{aligned}
& \hat{p}_{f}=\frac{1}{2 \pi}\left[a \operatorname{cov}_{0}+2 \sum_{k=1}^{T-1} a \operatorname{cov}_{(k)} \cos \frac{2 \pi}{T} f k\right] \\
& \text { Where: } 0 \leq\left(\frac{2 \pi}{T}\right) \leq \pi f=\frac{1}{T} i_{\mathrm{si}} 0 \leq f \leq 0,5 .
\end{aligned}
$$

"Density function" is useful in identifying areas where semiconductor increases are recorded and its estimate is given by the relationship:

$$
\begin{aligned}
& d_{(f)}=\frac{\hat{p}_{f}}{\hat{\sigma}_{f}}=2\left[1+2 \sum_{k=1}^{\infty} r_{k} \cos 2 \pi \cdot f k\right] \\
& \quad 0 \leq f \leq \frac{1}{2}, \\
& \text { Where: } \\
& r_{k} \text { represents the coefficient of autocorrelation. }
\end{aligned}
$$

In the first part of the article I will analyze the evolution of the number of employees of the distribution company of metal building materials using the STATISTICA economic analysis program, which can provide the technical support of such an analysis, having in the operating modules the one called "Spectral analyses". Monthly data pertaining to the number of employees are taken from the company's accounting records. The time period for which data was collected represents the interval between 2010 and 2017. The analyzed data series summed up ninety-six data sufficient for such a spectral analysis given the minimum empirical number demonstrated by the sixty data required for an efficiency analysis.

The number of employees for each month of the analyzed period is structured in Table 1.

Table 1. Number of company employees between 2010 and 2017

\begin{tabular}{|l|c|c|c|c|c|c|c|c|}
\hline \multicolumn{1}{|c|}{ MONTH } & year 2010 & year 2011 & year 2012 & year 2013 & year 2014 & year 2015 & year 2016 & year 2017 \\
\hline January & 9 & 8 & 9 & 11 & 12 & 11 & 12 & 13 \\
February & 9 & 7 & 9 & 11 & 12 & 11 & 12 & 13 \\
March & 9 & 7 & 9 & 11 & 12 & 11 & 12 & 11 \\
April & 9 & 8 & 10 & 10 & 12 & 11 & 12 & 11 \\
May & 9 & 8 & 10 & 11 & 12 & 11 & 12 & 11 \\
June & 9 & 8 & 10 & 11 & 12 & 12 & 12 & 11 \\
July & 9 & 8 & 11 & 11 & 12 & 12 & 12 & 11 \\
August & 9 & 8 & 11 & 11 & 12 & 12 & 13 & 11 \\
September & 9 & 8 & 11 & 11 & 11 & 12 & 13 & 11 \\
October & 9 & 8 & 11 & 11 & 11 & 12 & 13 & 11 \\
November & 8 & 9 & 11 & 11 & 11 & 12 & 13 & 10 \\
December & 8 & 9 & 11 & 12 & 11 & 12 & 13 & 10 \\
\hline
\end{tabular}

Source: The company's accounting data for the period from 2010 to 2017.

Following the graphical representation of the evolution of the number of employees during the analyzed period we can observe a oscillatory evolution of the small amplitude of this indicator.

The evolution of the number of employees in the period between 2010 and 2017 is presented in Figure 1.

After processing the data with the STATISTICA program, the important results of the spectral analysis of the number of employees of the distribution company, representing maximum variations in amplitude, are presented in Table 2. Table 2 shows both periodogram and spectral density values for different frequencies and time periods, as well as Fourier coefficient values. Periodogram representations and spectral density values are presented in Figure 2 and Figure 3. 


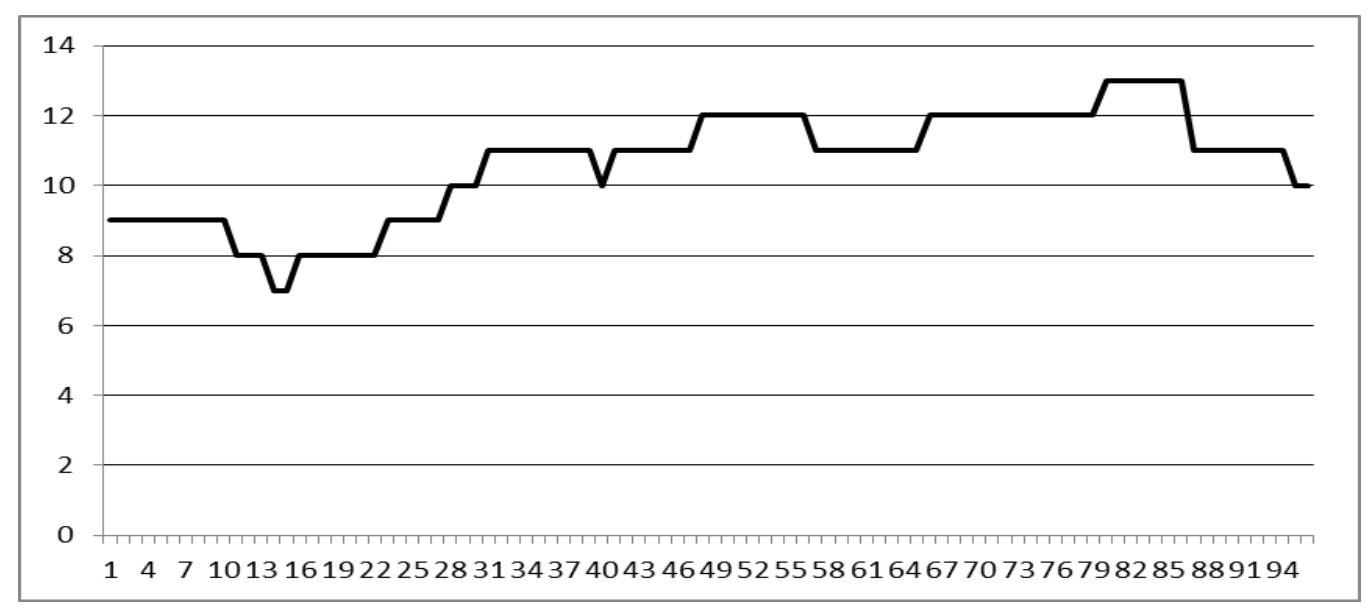

Source: The company's accounting data for the period from 2010 to 2017.

Figure 1. Evolution of the number of employees between 2010 and 2017

Table 2. Outstanding results in the spectral analysis of the number of employees

\begin{tabular}{|c|c|c|c|c|c|c|}
\hline $\begin{array}{c}\text { STAT. } \\
\text { TIME SERIES }\end{array}$ & \multicolumn{5}{l}{$\begin{array}{l}\text { Spectral analysis: VAR1 } \\
\text { No. of cases: } 96 \\
\text { Largest Periodog. values }\end{array}$} \\
\hline & Frequency & Period & Cosine Coeffs & Sine Coeffs & Periodogram & Density \\
\hline 1 & 0,010417 & 96,00000 & $-0,784008$ & $-0,293472$ & 33,63812 & 15,68290 \\
\hline 4 & 0,041667 & 24,00000 & 0,043729 & 0,622612 & 18,69879 & 8,79730 \\
\hline 6 & 0,062500 & 16,00000 & 0,147155 & 0,425591 & 9,73357 & 6,68971 \\
\hline 2 & 0,020833 & 48,00000 & 0,075329 & $-0,342223$ & 5,89397 & 12,69504 \\
\hline 3 & 0,031250 & 32,00000 & $-0,011518$ & 0,330339 & 5,24430 & 13,57822 \\
\hline 5 & 0,052083 & 19,20000 & $-0,210616$ & 0,218263 & 4,41589 & 7,70652 \\
\hline 13 & 0,135417 & 7,38462 & 0,042077 & 0,170878 & 1,48655 & 0,87646 \\
\hline 16 & 0,166667 & 6,00000 & 0,136323 & 0,055697 & 1,04094 & 0,70564 \\
\hline 12 & 0,125000 & 8,00000 & 0,036471 & 0,138346 & 0,98254 & 0,73615 \\
\hline 14 & 0,145833 & 6,85714 & 0,003715 & 0,137794 & 0,91205 & 1,05194 \\
\hline
\end{tabular}

Source: The company's accounting data for the period from 2010 to 2017.

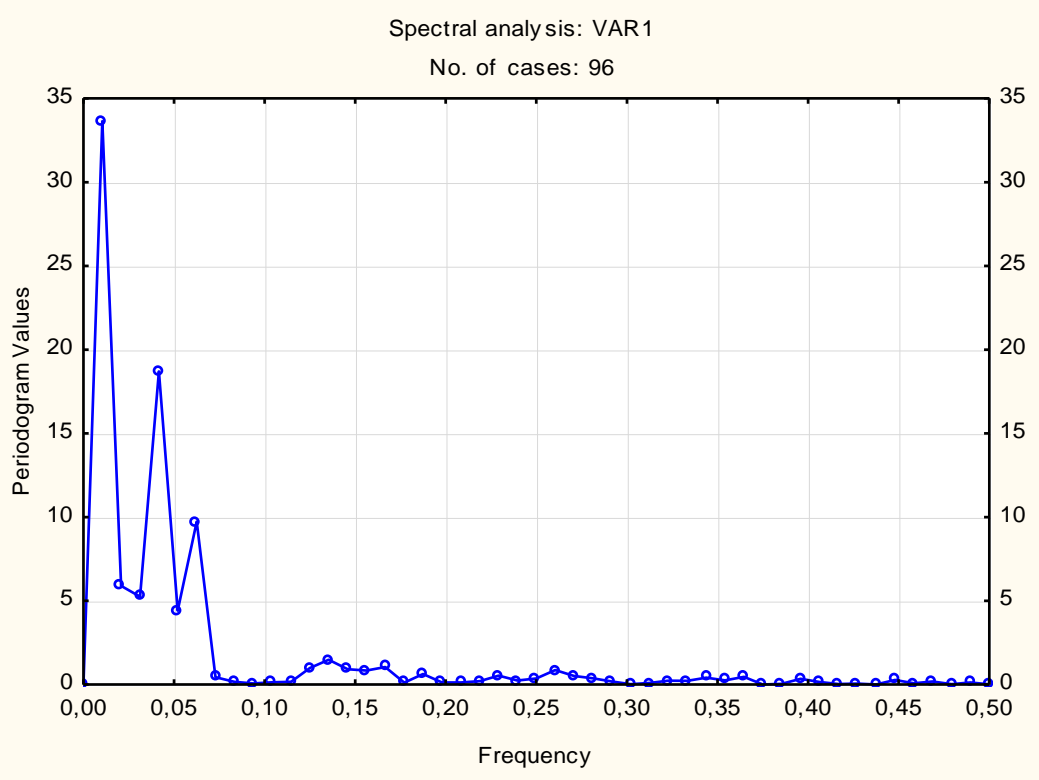

Source: The company's accounting data for the period from 2010 to 2017

Figure 2. Periodogram representation by frequency 


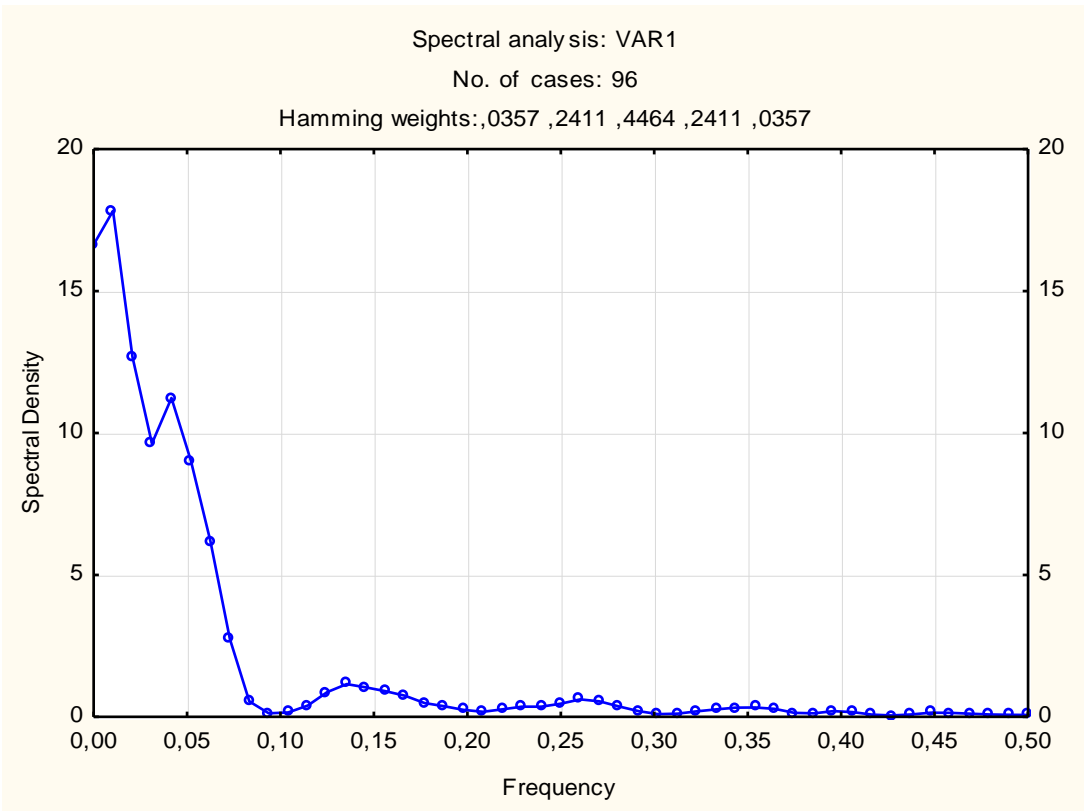

Source: The company's accounting data for the period from 2010 to 2017

Figure 3. Spectral density representation by frequency

In Figure 2 we have in the horizontal plane represented the frequency and its harmonics up to 0.50 . The values are obtained by summing the squares of the coefficients and multiplying the result of the addition by $T / 2$. Basically, we have an exponential relationship between the periodogram values and the amplitude values given that in both computing relations for the two variables we have a basis represented by the sum of the coefficients squares. The difference is that for the calculation of the periodogram the sum of the squares is multiplied by $T / 2$, and the value of the amplitude is determined as the square root of the same sum of the squares of the coefficients. Therefore, for the maximum values of the periodogram, we will have maximum amplitude values in correspondence. The dependence of the amplitude on the priodogram can be determined with the relation:

$A=\sqrt{\frac{2 \cdot V_{p}}{T}}$

Where: $A=$ amplitude;

$V_{p}=$ the value of the periodogram;

$T=$ number of time units of the series (number of months).

According to the results of the analysis regarding the indicator that was taken into account, the number of employees, it is evident that the analyzed indicator is not influenced by the seasonality. According to the results it is observed that the values of the periodogram recorded in Table 2 column 6 for periods less than one year have values less than 1.48655 .

At the same time, the spectral analysis made by the distribution company, indicating the number of employees for a period of nine and six months between 2010 and 2017, led to results showing the presence of cyclicality, which is confirmed by the maximum values record them in the sixth column of Table 2 for periods longer than one year (for ninety-six months, twenty-four months, sixteen months). The phenomenon can also be seen by viewing the data in graph 1 , which states that although there were fluctuations in the number of employees in the eight years, there was a major approximation of the number of employees during 2010 by 2017.

As far as the spectral density is concerned, it is characterized by significant increases at periods of ninety-six months, twenty-four months and sixteen months respectively (graph 3 ). We observe that these increases in spectral density are analogous to the peaks of the values recorded in the periodogram for 
amplitude, phenomenon expected otherwise given that the density function is the first derivative of the function spectrum of the process.

The second part of the article is the application of spectral analysis indicating the profit that the distribution company had in the period between 2013 and 2017. The data series will include a number of sixty months for the mentioned period. Thus, the profit or loss expressed in ROL for each month of the analyzed period is structured in Table 3.

Table 3. Profit or loss for the period between 2013 and 2017

\begin{tabular}{|l|c|c|c|c|c|}
\hline \multicolumn{1}{|c|}{ MONTH } & year 2013 & year 2014 & year 2015 & year 2016 & year 2017 \\
\hline January & -6695 & -4189 & -17509 & -23398 & -37869 \\
February & 266 & 388 & -19104 & 29586 & -14278 \\
March & 1720 & 425 & -19733 & -1511 & 5880 \\
April & 726 & 558 & 10147 & -28148 & -30806 \\
May & -205 & 488 & -9492 & 31816 & 50838 \\
June & 1924 & 6470 & -1964 & 6207 & 32094 \\
July & 1745 & 645 & -19256 & 3195 & 1242 \\
August & 1201 & -4983 & -2369 & 2452 & 402 \\
September & 419 & 628 & 11336 & 5431 & -1568 \\
October & 3381 & -3721 & 37300 & -9620 & 1758 \\
November & 1524 & 2166 & 19778 & 2574 & 850 \\
December & -677 & 4712 & 13730 & -17040 & -7237 \\
\hline
\end{tabular}

Source: Company balances for the period from 2013 to 2017

The evolution of the company's profitability in the analyzed period is represented in Figure 4:

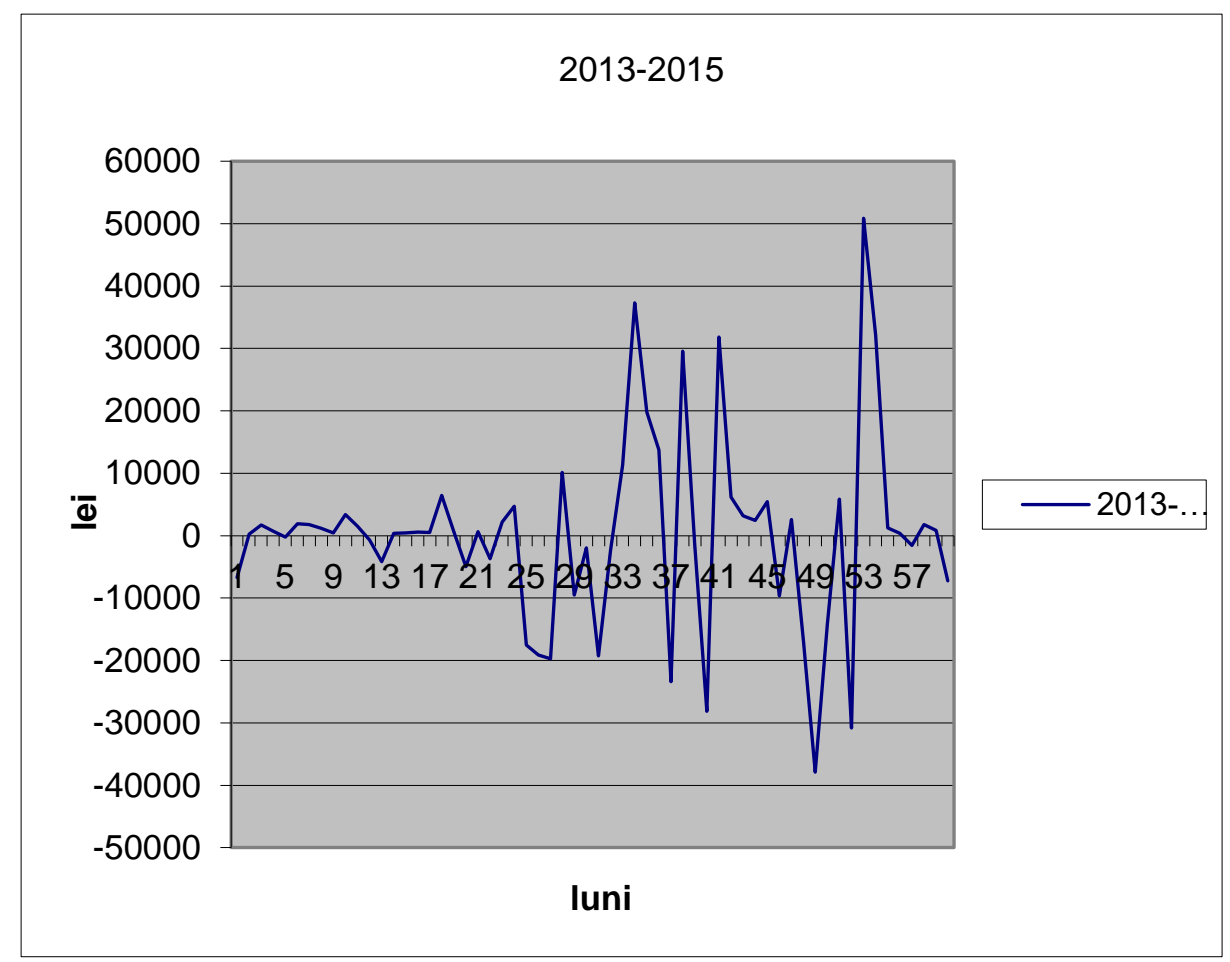

Source: Company balances for the period from 2013 to 2017

Figure 4. Profit evolution over the period from 2013 to 2017

Figure 4 shows the oscillations of different amplitudes of profits made by the company between 2013 and 2017. High amplitudes of oscillations are observed in the period between 2015 and 2017, a period characterized by major changes in the market of materials construction in relation to the price of marketed products correlated with major economic policy measures. 
After the data processing with the economic analysis program, the important results of the spectral analysis of the evolution of the profit of the distribution company are presented in Table 4:

Table 4. Spectral analysis, values calculated for profit analysis

\begin{tabular}{|c|c|c|c|c|c|c|}
\hline $\begin{array}{l}\text { STAT. } \\
\text { TIME SERIES }\end{array}$ & \multicolumn{5}{l|}{$\begin{array}{l}\text { Spectral analysis: VAR1 } \\
\text { No. of cases: } 60 \\
\\
\end{array}$} \\
& Largest Periodog. values & \\
\hline & Frequency & Period & Cosine Coeffs & Sine Coeffs & Periodogram & Density \\
\hline 6 & 0,100000 & 10,00000 & $-1487,63$ & 6498,71 & $1,333390 \mathrm{E}+09$ & 954237346 \\
\hline 20 & 0,333333 & 3,00000 & $-6234,23$ & 1540,31 & $1,237147 \mathrm{E}+09$ & 963081941 \\
\hline 3 & 0,050000 & 20,00000 & 668,77 & $-6040,70$ & $1,108118 \mathrm{E}+09$ & 706614701 \\
\hline 10 & 0,166667 & 6,00000 & $-3946,57$ & $-4037,12$ & $9,562117 \mathrm{E}+08$ & 535336203 \\
\hline 19 & 0,316667 & 3,15789 & $-2452,19$ & $-4856,18$ & $8,878716 \mathrm{E}+08$ & 838858351 \\
\hline 5 & 0,083333 & 12,00000 & $-5280,82$ & $-1072,37$ & $8,711097 \mathrm{E}+08$ & 840801223 \\
\hline 24 & 0,400000 & 2,50000 & 4515,15 & $-2623,42$ & $8,180680 \mathrm{E}+08$ & 497584649 \\
\hline 21 & 0,350000 & 2,85714 & 1722,52 & 4662,38 & $7,411460 \mathrm{E}+08$ & 674864832 \\
\hline 12 & 0,200000 & 5,00000 & $-4539,47$ & 497,43 & $6,256263 \mathrm{E}+08$ & 358473721 \\
\hline 7 & 0,116667 & 8,57143 & 4170,65 & 1261,33 & $5,695585 \mathrm{E}+08$ & 626611388 \\
\hline
\end{tabular}

Source: Company balances for the period from 2013 to 2017.

Figures 5 and 6 are representations of periodogram values and spectral density according to frequency.

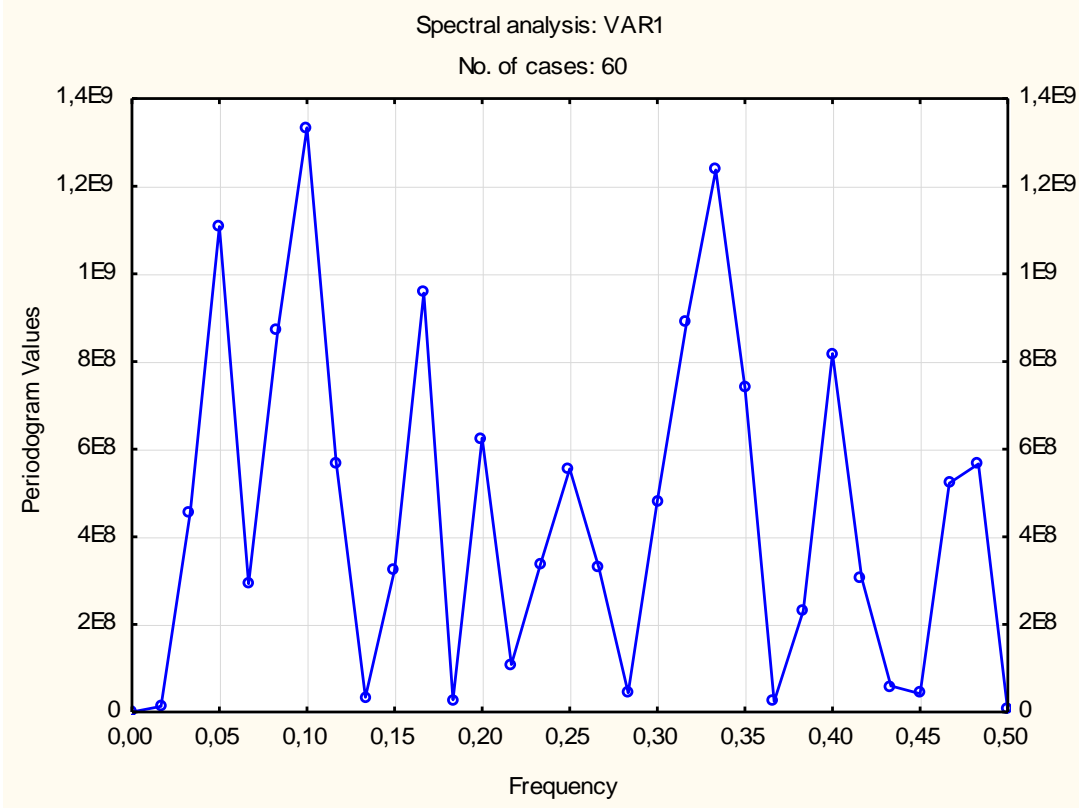

Source: Company balances for the period from 2013 to 2017

Figure 5. Periodogram representation by frequency

It can be seen that the most important oscillation, which has the highest amplitude, appears at ten months, and the size of the corresponding periodogram has the value of 1.333390 multiplied by ten to nineth power. Also, the great amplitude is recorded for the harmonics of this period, namely twenty months. A second apple amplitude value is recorded at three months, followed by the harmonics of this period at six months and twelve months respectively, periods where amplitude values are high (column six Table 4). 


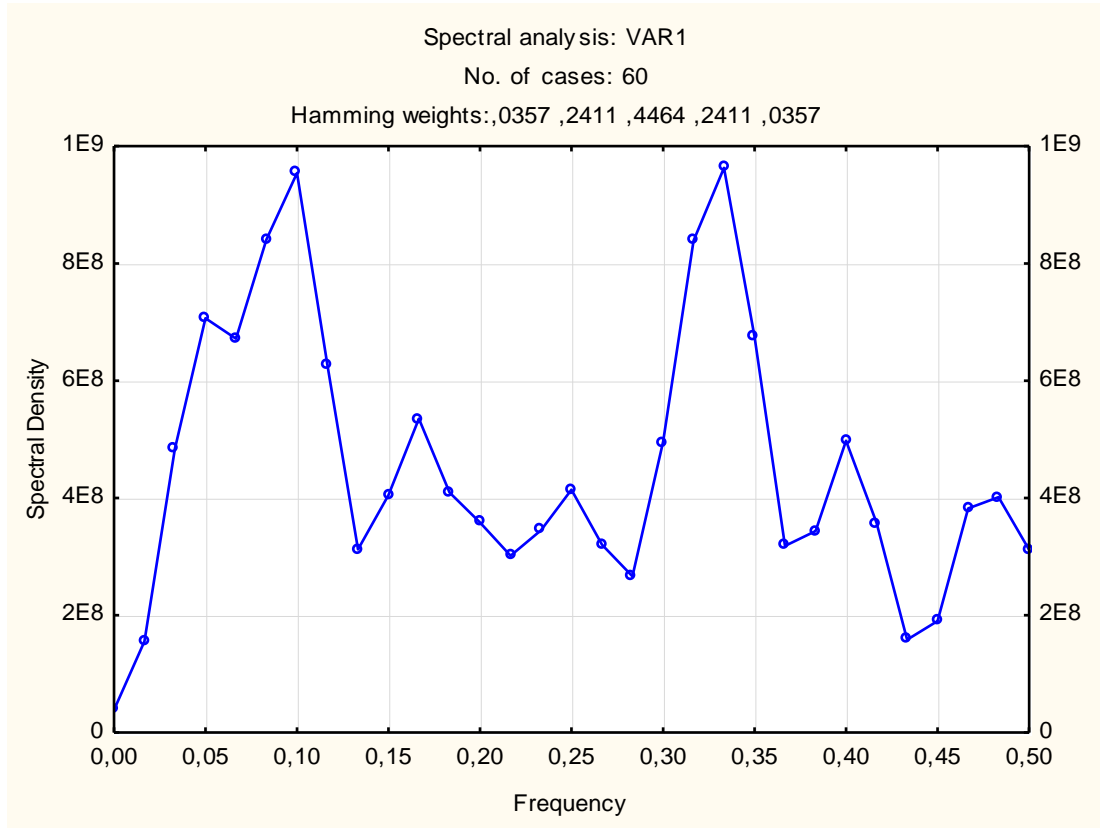

Source: Company balances for the period from 2013 to 2017

Figure 6. Spectral density representation by frequency

Since for frequencies of periods of less than a year (in the case of three months, six months, ten months and twelve months) the amplitude is high, we are shown the strong presence of the company's profit seasonality.

As for the trend in the series data (readily identifiable in Figure 4), it is not signaled. An indication in this respect is the low amplitude values for frequencies lower than the unit value (signaled by the periodogram in Table 4, column six and represented in Figure 5).

Due to the relatively small amplitudes recorded for periods of more than one year (except for the one recorded at twenty months), they lead to the conclusion that the presence of cyclicity cannot be confirmed.

\section{Conclusions}

Although the first indicator analyzed in this paper, the number of employees of the metal building materials distribution company, is not influenced by seasonality, I still consider that the conditions in which these companies carry out their business impose the need to approach a seasonal employment policy. I can argue that Romania geographically has a position that is strongly influenced by the environmental conditions dictated by the four seasons. With the accession of Romania to the European Union, the labor migration phenomenon has gained momentum and Romania has faced a situation of maximum exploitation of the labor force with a shortage of personnel. Practically, the employment of human resources during peak seasonal periods has become almost impossible in Romania, migrating due to seasonal coincidences with other EU Member States, where the salary level has major differences. This aspect justifies the decrease of the profit of the distribution company in the area of micro-enterprises in Romania which, in order to carry out its activity, has to employ staff for indefinite periods regardless of the season. Expenditures of the company with excess of personnel for periods of activity are directly reflected in the income statement. This is confirmed by the second analysis of the company's profits, which is strongly influenced by seasonality.

Cyclicality of the number of employees is economically justifiable because, due to the rise in building materials prices, there is an increase in profitability for the same amount of work. Given that sales remain at the pre-price level but with higher added value (with higher markup), the workforce under the initial conditions is no longer justified, and reorganization measures (staff reduction) are needed. 
At the same time, long-term sales stagnation coupled with significant price increases, as they have been over $60 \%$ over the past two years, indicate the approach of a new cycle. In other words, I consider that the number of employees can be a serious signal for what is going to happen at the level of future sales (their significant decrease).

Considering the financial and accounting data they have at the administration of the companies over the periods experienced due to the current activity, I believe that at a microeconomic level, a spectral analysis of these data can give important information about the evolution of the business in terms of seasonality, economic cyclicality and the possibilities of its development.

\section{References}

1. Brenneke, R., Schuster, G. (1973), Fizică, Ed. Didactică si Pedagogică București.

2. Bulinski, M. (2007), Econofizică și complexitate, Ed. Univ. București.

3. Ceanga, E., Munteanu, I., Bratcu, A., Culea, M. (2001), Semnale, circuite și sisteme. Analiza semnalelor, Editura Academica.

4. Danet, A.F. (2010), Analiză instrumentală, Ed. Univ. București.

5. Gheorghiu, A., Spanulescu, I. (2007), Noi abordări și modele econofizice, Ed. Economica.

6. Granger, C.W.J., Hatanaka, M. (1964), Spectral Analysis of Economic Time Series, Princeton University Press, Princeton, New Jersey.

7. Iacobucci, A. (2003), Spectral Analysis for Economic Time Series.

8. Isaic-Maniu, A., Mitrut, C., Voineagu, V. (2004), Statistică, Ed. Universala București.

9. Nave, C.R. (2006). "Hydrogen Spectrum". HyperPhysics. Georgia State University. Retrieved March $1,2008$.

10. Pecican, E.S. (2009), Econometria pentru economiști, Ed. Economică București.

11. Peijie Wang, Trefor J. (2010), A Spectral Analysis of Business Cycle Patterns in UK Sectoral Output.

12. Priestley, M.B. (1971), Time-dependent spectral analysis and its application in prediction and control, Journal of Sound and Vibration.

13. Priestley, M.B. (1996), Sprectral Analysis and Time Seties, Academic Press London.

14. Reif, F. (1983), Fizică statistică (Berkeley vol. V), Ed. Didactică și Pedagogică București. 